\title{
Significados da Dor Crônica na Sobrevivência ao Câncer de Mama
}

doi: https://doi.org/10.32635/2176-9745.RBC.2021v67n1.1143

\author{
Meanings of Chronic pain in Breast Cancer Survival \\ Significados del Dolor Crónico en la Supervivencia del Cáncer de Mama
}

Paloma Gomes'; Fernando Lopes Tavares de Lima²; Antonio Tadeu Cheriff dos Santos ${ }^{3}$

RESUMO

Introduçáo: A dor crônica é um problema comum em sobreviventes de câncer de mama. Objetivo: Compreender os significados atribuídos por mulheres, sobreviventes de câncer de mama, à experiência de viver com dor crônica. Método: Para alcance dos objetivos, realizou-se uma pesquisa qualitativa com base na hermenêutica-dialética, em hospital de referência em oncologia do Rio de Janeiro. Foram realizadas entrevistas semiestruturadas com seis sobreviventes de câncer de mama de longo prazo, entre julho e outubro de 2018. Resultados: Quatro abrangentes sentidos sociais ganham relevo no material empírico: dor como consequência do tratamento; dor como um processo cenestésico; dor como tributo à doença sofrida; e dor como expressão de afetos e apegos. São relatos que apontam para um balanço da experiência como busca de uma explicação para a dor total sentida. A sobrevivência é experienciada como um processo de transição, aceitação e construção de novas identidades biográficas que só são possíveis de serem compreendidas e cuidadas, levando-se em conta as dimensóes biológica, emocional, social e espiritual. Conclusão: As narrativas partem de uma dor como fragmentação, murmúrio e monólogo do corpo, para uma situação de convívio, expressão de afetos e aceitação da dor como transiçáo para sobrevivência. O estudo reforça a necessidade da estruturação de uma linha de cuidados que tenha na escuta ativa e qualificada das narrativas de dor o ponto básico para o desenvolvimento de um cuidado na sobrevivência ao câncer humanizado.

Palavras-chave: Dor Crônica; Sobrevivência; Neoplasias da Mama; Pesquisa Qualitativa.

\section{ABSTRACT}

Introduction: Chronic pain is a common problem in breast cancer survivors. Objective: Understand the meanings attributed by women breast cancer survivors to the experience of living with chronic pain. Method: To reach the objectives, a qualitative research based on hermeneutic-dialectic was carried out in a reference oncology hospital in Rio de Janeiro. Semi-structured interviews were conducted with six long-term breast cancer survivors between July and October 2018. Results: Four broad social meanings are highlighted in the empirical material: pain as a result of treatment; pain as a kinesthetic process; pain as a tribute to the disease suffered; and pain as an expression of affections and attachments. These are narratives that accentuate the experience lived while searching for an explanation for the full pain felt. Survival is experienced as a process of transition, acceptance and construction of new biographical identities that are only possible to be understood and cared for taking into account the biological, emotional, social and spiritual dimensions. Conclusion: The narratives start from a pain as fragmentation, murmur and monologue of the body, to a situation of conviviality, expression of affections and acceptance of pain as a transition to survival. The study reinforces the need for structuring a care line that has as basic core the active and qualified listening of pain narratives for the development of humanized care in cancer survival.

Key words: Chronic Pain; Survivorship; Breast Neoplasms; Qualitative Research.

\section{RESUMEN}

Introducción: El dolor crónico es un problema comun en los supervivientes de cáncer de mama. Objetivo: Comprender los significados atribuidos por las mujeres, sobrevivientes de cáncer de mama, a la experiencia de vivir con dolor crónico. Método: Se realizó una investigación cualitativa con base en la hermenéutica-dialéctica, en hospital de referencia en oncología de Río de Janeiro. Se realizaron entrevistas semiestructuradas con seis sobrevivientes de cáncer de mama a largo plazo entre julio y octubre de 2018. Resultados: En el material empírico se destacan cuatro significados sociales amplios: dolor como resultado del tratamiento; El dolor como proceso cenestésico; El dolor como tributo a la enfermedad sufrida; y el dolor como expresión de afectos y apegos. Se trata de relatos que apuntan a un equilibrio de la experiencia como búsqueda de una explicación al dolor total sentido. La supervivencia se vive como un proceso de transición, aceptación y construcción de nuevas identidades biográficas que solo se pueden comprender y cuidar teniendo en cuenta las dimensiones biológica, emocional, social y espiritual. Conclusión: Las narrativas parten de un dolor como fragmentación, murmullo y monólogo del cuerpo, a una situación de convivencia, expresión de afectos y aceptación del dolor como transición a la supervivencia.El estudio refuerza la necesidad de la estructuración de una línea de cuidados que tenga en la escucha activa y calificada de las narrativas de dolor el punto básico para el desarrollo de un cuidado en la supervivencia al cáncer humanizado.

Palabras claves: Dolor Crónico; Supervivencia; Neoplasias de la Mama; Investigación Cualitativa.

\footnotetext{
1,2,3 Instituto Nacional de Câncer José Alencar Gomes da Silva (INCA). Rio de Janeiro (RJ), Brasil.

'Programa de Residência Multiprofissional. E-mail: palomagomex@gmail.com. Orcid iD: https://orcid.org/0000-0001-7797-7440

${ }^{2}$ Coordenação de Ensino. E-mail: flima@inca.gov.br. Orcid iD: https://orcid.org/0000-0002-8618-7608

${ }^{3}$ Divisão de Pesquisa Populacional/Núcleo de Pesquisa e Estudos Qualitativos. E-mail: cheriff@inca.gov.br. Orcid iD: https://orcid.org/0000-0002-3577-0772

Endereço para correspondência: Antonio Tadeu Cheriff dos Santos. Rua Marques de Pombal, 125, $7{ }^{\circ}$ andar - Centro. Rio de Janeiro (RJ), Brasil. CEP 20230-240.

E-mail: cheriff@inca.gov.br
} 


\section{INTRODUÇÃO}

Excetuando-se o câncer de pele não melanoma, o câncer de mama é o segundo câncer mais incidente do mundo e o mais frequente entre mulheres, com aproximadamente 2,1 milhōes de novos casos no mundo ${ }^{1}$. No Brasil, as estimativas apontam, aproximadamente, para cada ano do triênio 2020-2022, 66 mil novos casos de câncer de mama ${ }^{2}$. Em virtude das novas formas de diagnóstico e tratamento, tem-se aumentado o número de pessoas que conseguem sobreviver por longos períodos, trazendo inúmeros desafios ao sistema de saúde e social.

O conceito de sobrevivência em oncologia é discutido desde a década de 1980. Para Mullan ${ }^{3}$, a sobrevivência se inicia no momento do diagnóstico da doença, pois é nesse momento que os pacientes são forçados a enfrentar sua finitude e começam a fazer os ajustamentos para o seu futuro imediato e de longo prazo. Para o autor, a experiência da sobrevivência deve ser entendida como uma longa jornada, não só de busca da cura e/ou tratamento, mas também compreensão e mitigação dos impactos clínicos, emocionais e sociais ao longo do processo, desde o diagnóstico até o final da vida do indivíduo. A dor é um dos problemas que atinge os sobreviventes de câncer, podendo durar meses, anos ou até mesmo uma vida ${ }^{4}$.

Do ponto de vista da dor, a definição de sobrevivência de Mullan ${ }^{3}$ abrange o estágio da doença desde o diagnóstico (quando o próprio tumor pode estar causando dor), perpassando o tratamento (que geralmente resulta em dor), até um estado de cura da doença (no qual formas mais persistentes de dor são frequentemente encontradas) $)^{5}$.

Nesse sentido, mais do que uma definição em termos biomédicos, a dor crônica é compreendida como sendo uma persistente experiência sensorial e emocional desagradável associada a um dano tissular real ou potencial, ou descrita em termos de tal dano. A dor é, portanto, o que o indivíduo diz sentir e padecer ${ }^{6-8}$. Em termos clínicos, a International Association for the Study of Pain (IASP) define a dor crônica como uma dor persistente ou recorrente duradoura por mais de três meses, podendo ser causada pelo próprio câncer e/ou por seu tratamento ${ }^{8}$.

Todas as modalidades terapêuticas do câncer de mama, isoladas ou combinadas, têm o potencial de causar dor crônica'. Vale ressaltar que $41 \%$ das sobreviventes do câncer de mama apresentam queixas de dor entre um e cinco anos de pós-tratamento ${ }^{4}$.

A dor crônica em sobreviventes de câncer de mama possui elementos pouco conhecidos e não contemplados nas atuais linhas de cuidados e protocolos, principalmente no que se refere às questôes que extrapolam a abordagem biomédica. Poucos estudos abordam e registram as necessidades peculiaridades desse grupo a partir das suas experiências e vivências ${ }^{4}$.

Este artigo objetiva compreender os significados atribuídos por mulheres, sobreviventes de câncer de mama, à experiência de viver com dor crônica. Espera-se que seus resultados forneçam aos profissionais de saúde mais informaçóes sobre os desafios e dificuldades singulares que as sobreviventes câncer de mama de longo prazo com dor crônica enfrentam, de forma que possam ser desenvolvidas intervençôes terapêuticas apropriadas para melhorar o seu cuidado e qualidade de vida.

\section{MÉTODO}

Trata-se de pesquisa qualitativa exploratória, fundamentada na hermenêutica-dialética. A união da hermenêutica com a dialética permite a condução de um processo ao mesmo tempo compreensivo e crítico das atribuiçôes simbólicas às experiências de vida ${ }^{10}$.

A pesquisa foi realizada em um hospital de referência em oncologia do Rio de Janeiro, entre julho e outubro de 2018. A seleção das participantes envolveu uma amostragem por conveniência a partir da consulta aos prontuários médicos, considerando os seguintes critérios de inclusão: mulheres, maiores de 18 anos, livres de doença neoplásica, com um tempo de diagnóstico de qualquer subtipo de câncer de mama há pelo menos cinco anos, com diagnóstico médico de dor crônica decorrente do tratamento oncológico, matriculadas e em acompanhamento por clínica especializada de controle da dor, que finalizaram o tratamento oncológico.

O material discursivo foi obtido por meio de seis entrevistas individuais semiestruturadas, orientadas por um roteiro elaborado especificamente para o estudo, com foco na experiência da sobrevivência e do controle da dor crônica decorrente do tratamento oncológico. As entrevistas foram conduzidas por pesquisadora especialista em oncologia. Dada a tradição crítico-interpretativa com a qual esta pesquisa é afiliada, o fechamento da amostra baseou-se no princípio do "poder da informaçâo"11.

As participantes foram convidadas logo após as suas consultas no ambulatório de dor, não havendo recusas. As entrevistas tiveram média de 40 minutos e foram realizadas, em uma única vez, em salas reservadas na unidade hospitalar, audiogravadas e, posteriormente, transcritas, permitindo a leitura compreensiva do material. Foram levantados também os perfis sociodemográfico (idade, raça, escolaridade, estado civil, religião, naturalidade e procedência) e clínico (tratamento antineoplásico, tempo do término do tratamento, tempo livre de doença, tempo de dor relacionada ao tratamento, tempo de acompanhamento pela Clínica da Dor) referentes às participantes. 
Para organização, análise e interpretação do material, realizaram-se: (a) leitura compreensiva; (b) codificação do material e identificação dos sentidos subjacentes às falas dos participantes; (c) problematização das ideias e dos sentidos presentes nos depoimentos e articulação com significados socioculturais; (d) elaboração de síntese entre os dados empíricos, informaçôes provenientes de outros estudos acerca do assunto, referencial teórico/ conceitual do estudo e aportes teóricos adicionais que se fizeram necessários.

A categorização e a análise foram realizadas pelos pesquisadores conjuntamente, considerando convergências e divergências de significados e a recorrência das citaçôes discursivas. As entrevistas foram transcritas literalmente. Os autores, trabalhando de forma independente, validaram cada transcrição. Todas as transcriçôes foram verificadas e comparadas com as gravaçóes originais e as notas de campo do entrevistador. A codificação dos fragmentos das falas oriundas das transcriçõos segue a seguinte notação: E (entrevistado), seguida da numeração arábica, de acordo com a ordem cronológica de realização das entrevistas. Para a interpretação do material, foi adotada a análise temática do discurso alinhada à abordagem crítico-interpretativa, articulada aos contextos sociocultural e clínico ${ }^{12}$.

O referencial teórico que serviu de base para a análise e síntese de sentidos do material empírico foi a concepção de dor a partir de um modelo biopsicossocial, no qual a dor crônica é entendida com um processo recíproco e dinâmico entre variáveis biológicas, psicológicas, socioculturais e espirituais ${ }^{13}$. São relacionados nesse horizonte conceitual: a definição da IASP ${ }^{6}$; a classificação de dor total de Cicely Saunders, por sua visão abrangente e integral da dor e da paliaçãa ${ }^{14}$; as abordagens socioculturais da dor de Le Breton $^{15-17}$ e de Zborowski ${ }^{18}$. Todas funcionando como contrapontos às abordagens estritamente biológicas e medicalizantes que buscam controlar de forma padronizada a dor.

A pesquisa foi aprovada pelo Comitê de Ética em Pesquisa da instituição, CAAE: 91180218.7.0000.5274, e respeitou as normas de pesquisa estabelecidas nacionalmente.

\section{RESULTADOS E DISCUSSÃO}

O perfil das participantes abrange idades entre 48 e 67 anos, sendo a maioria aposentada (83\%) e com estado civil solteira (66\%). Duas (33\%) tinham o ensino fundamental incompleto, duas (33\%) o ensino fundamental completo, uma $(16 \%)$ o ensino médio completo, e uma (16\%) o ensino superior completo. Quanto à raça, metade se declarou branca e metade parda. Sobre aspectos religiosos, $50 \%$ se declararam católica, $33 \%$ evangélica e $16 \%$ não mencionaram sua crença. Quatro entrevistadas (66\%) são naturais do Rio de Janeiro, uma (16\%) de Minas Gerais, e uma (16\%) da Paraíba. Apesar da heterogeneidade dos perfis, não houve diferenças quanto à compreensão e dificuldades na atribuiçáo de sentidos e enfrentamento da dor crônica.

No que se refere ao histórico clínico, constatou-se que todas realizaram tratamento cirúrgico e quimioterápico para câncer de mama, sendo que $83 \%$ realizaram radioterapia e esvaziamento axilar. Mais da metade das participantes (66\%) também se submeteram à supressão hormonal (66\%). O tempo de diagnóstico de câncer variou entre cinco e 15 anos (mediana de 8,5 anos). O tempo de dor relacionada ao tratamento oncológico variou de quatro a 14 anos (mediana de 8,5 anos). Em relação ao acompanhamento na Clínica da Dor, verifica-se um atraso no início do acompanhamento especializado, tendo em vista que a mediana de tempo para o início do acompanhamento pela clínica foi de 7,5 anos (variando entre dois e nove anos).

Os resultados do presente artigo apresentam os significados mais relevantes destacados pelas entrevistadas. São relatos que apontam para um balanço da experiência como busca de uma explicaçáo para a dor total sentida, como uma experiência única, integrada e multidimensiona ${ }^{14}$, abrangendo os sofrimentos físico, emocional, social e espiritual. Os relatos que compóem as categorias "Dor como consequência do tratamento", "Dor como um processo cenestésico" e "Dor como tributo à doença sofrida" são marcados pela experiência de um sofrimento singular que acompanha a sobrevivência dessas mulheres. As narrativas apontam também, na categoria "Dor como expressáo de afetos e apegos", para a construção de novos sentimentos e significados da dor sentida; ou seja, um processo de transição, aceitação e construção de novas identidades biográficas que só são possíveis de serem compreendidas e cuidadas levando-se em conta as dimensóes biológica, emocional, social e espiritual dessas mulheres como sujeitos únicos na expressão e enunciação de suas dores sofridas.

Esses significados e sentidos se aproximam de estudos similares sobre o tema da dor crônica em sobreviventes de câncer mama ${ }^{19-24}$. São estudos que discorrem sobre experiências vividas de sofrimento e incerteza sobre o futuro. Igualmente, são estudos em que as participantes normalizam suas dores de variadas formas: como um passo necessário no caminho da recuperação, como prova da eficácia do tratamento, ou mesmo como uma condição permanente com a qual deve-se aprender a conviver ${ }^{20}$. Em todos, no entanto, fica patente a necessidade de que as sobreviventes do câncer de mama com dor crônica devem ser mais bem informadas, assistidas e estudadas, 
e escutadas em suas queixas e relatos, uma vez que a dor crônica compromete a qualidade de vida dessas pacientes $^{21-24}$.

\section{DOR COMO CONSEQUÊNCIA DO TRATAMENTO}

A dor como consequência do tratamento traduz o sentido de formulação, ainda fragmentado, de uma explicação da dor como um processo biológico que envolve o tratamento oncológico:

A doutora [da Clínica da Dor] me falou que têm pessoas que faz a cirurgia e náo sente nada. $E$ já têm outras que fica [com dor] para o resto da vida. (...) Tudo começou depois de tudo, da cirurgia, da quimio, da rádio, né, depois que mexeu, antes de mexer não tinha nada (E6).

Nessa e em outras falas, nota-se que as participantes identificam o caráter físico da dor do corpo, mas que é ainda insuficiente para explicá-la:

Deve ser provavelmente de onde cortaram, de onde tiveram que tirar alguma coisa, machucou, magoou alguma coisa (E4).

Foi devido ao tratamento de quimioterapia. Foi uma lesão nervosa devido à quimioterapia (E2).

Le Breton ${ }^{15,16}$ ressalta que a anatomia e a fisiologia são insuficientes para explicar as variaçóes culturais, sociais, pessoais e, até mesmo contextuais, que afetam um indivíduo por ocasião de uma experiência dolorosa. Isso ocorre porque a atitude em relação à dor não é algo meramente mecânico ou fisiológico, mas é também mediada pela cultura, pelas variaçóes pessoais e pelo significado subjetivo atribuído à sua presença.

Seguindo a abordagem antropológica da dor de Le Breton ${ }^{16}$, a dor é impregnada do social, do cultural e do relacional, sendo fruto de uma educação. No caso das participantes desta pesquisa, essa situação aflora, sobretudo, com as explicaçóes de ordem biomédica aprendidas e adquiridas pelo diagnóstico e tratamento do câncer.

Eu entendi, pelas conversas, que eu tenho com o médico. Assim, vou pegando de um e de outro, eu vou vendo que foi cortada alguma coisa do sistema nervoso e aquilo ali fica sensível (E1).

A explicação da dor, no entanto, não escapa do vínculo das simbolizaçóes sociais ${ }^{15,16}$. Zborowski ${ }^{18}$, com sua abordagem sociológica sobre dor, aponta que reaçôes à dor manifestada por membros de diferentes grupos culturais não refletem necessariamente atitudes semelhantes à dor. Esses padrôes reativos, em termos das suas manifestações, podem ter diferentes funções e servir a diferentes propósitos.

A IASP ${ }^{6}$ define dor como sendo uma "experiência sensorial e emocional desagradável associada a um dano tissular real ou potencial, ou descrita em termos de tal dano". A dor é, portanto, o que o indivíduo diz sentir e padecer. Nesse sentido, a "dor total", termo empregado por Cicely Saunders, configura uma experiência única, integrada e multidimensional ${ }^{14}$, abrangendo os sofrimentos físico, emocional, social e espiritual, nos quais a natureza da dor no corpo vai para além dos aspectos físicos e de uma estrutura puramente orgânica, cuja lógica e funcionamento é simbólica ${ }^{25}$. Como o indivíduo é singular, não se pode pretender que todos respondam da mesma forma às intervençôes externas, nem que mantenham uniformemente suas respostas em longo prazo ${ }^{18}$.

Assim, verificou-se que a dor consequente ao tratamento oncológico é simbólica e funcionalmente manifestada, como normas de uma lógica e jargóes biomédicos que regulam e permeiam as interaçôes e justificativas sociais e narrativas das pacientes. Apesar disso, existem outros mecanismos sociais que podem influenciar as expressôes e manifestaçôes da dor total sentida. Os profissionais de saúde devem atentar para essas relaçôes, a fim de poderem melhor apoiar os seus pacientes em suas necessidades de cuidados.

\section{DOR COMO UM PROCESSO CENESTÉSICO}

A dor como um processo cenestésico caracteriza a dor total sentida como um pool de percepçóes e sensaçóes interligadas por processos sensoriais. São representações que carregam a consciência e a emoção do próprio corpo, de sua posição, de seu movimento, de sua postura em relaçáo ao mundo à sua volta e em relação às suas diversas partes e segmentos.

Tem dias que parece que vai rasgar, eu não sei o que é isso que estica de uma tal maneira, entendeu? [...] Tem hora que dá um choque, ao mesmo tempo vem coceira e você não sente nada, porque isso tudo é morto. Aí você coça, coça, mas você não acha a coceira, onde tá a coceira? (E5).

Esta e as demais falas dessa categoria se aproximam da recente proposta de Williams e Craig ${ }^{26}$, para uma nova definição de dor para $\mathrm{IASP}^{6}$. Nela, a dor é "uma experiência angustiante composta de elementos sensoriais, emocionais, cognitivos e sociais" ${ }^{26}$. Uma definição que reforça ainda mais a perspectiva do modelo biopsicossocial 
da dor, no qual as vias da dor são a sensação, a transmissão, a percepção e a reação, e as medidas de sensibilidade, assim como todos os demais mecanismos de dor, são individuais ${ }^{24}$.

Eu me sinto como se eu tivesse num moedor de carne. (...) Porque eu fico me contorcendo igualzinho. Como faz com a carne, pra moer a carne. (...) Ou passou um trator em cima de mim, alguma coisa assim. Parece que eu tô toda quebrada por dentro (E2).

Dessa forma, a dor total sentida se traduz em um sofrimento composto de elementos sensoriais e emocionais que permeiam as explicações e narrativas sociossimbólicas dessas pacientes. Isso serve de lembrança aos profissionais de saúde que, para além dos mecanismos sociais, as influências e cargas emocionais influenciam as expressóes e as manifestações da dor total sentida. Ignorá-las se traduz em importantes lacunas de um cuidado humanizado e integral.

\section{DOR COMO TRIBUTO À DOENÇA SOFRIDA}

A dor como um tributo à doença sofrida traduz um sentido de oferecer permissáo para sentir e sofrer em troca da remissão/cura do câncer. As falas caracterizam a dor total sentida como um carma, um pagamento daquilo que se propóe ser a cura do câncer.

Quando eu me livrei da doença e eu tive que pagar caro por isso. [...] Como eu me livrei da doença, isso aí é uma carga que eu tenho que carregar agora. Mas não é muito bom não, né, ter que pagar desse jeito. Mas, Deus me livre, nunca mais voltar essa doença. Eu prefiro conviver com a dor, do que, né, a doença vim e me levar, né. Deus me livre (E1).

Para Miceli ${ }^{27}$, a dor também possui caráter subjetivo e vem sendo historicamente compreendida e explicada de forma mítica, mística ou religiosa. Dor e sofrimento seriam inseparáveis e interpretados socialmente como merecidos castigos causados pelos deuses, ou mesmo martírios e provações para a purificação e a salvação da alma. Tais conceitos parecem estar no imaginário coletivo, haja vista que ainda hoje existem pacientes que se culpabilizam pela sua doença e dor, acreditando que para crescer e amadurecer é preciso sofrer.

Acho que isso aí faz parte do... É como é que se diz? Eu me livrei do câncer, mas ficou ali a lembrança dele, entendeu? (E4).

O câncer estava ali. Acabou o processo, acabou tudo. Mas esse... a gente fica com esse restinho do que a gente passou, é uma dor, é uma dor. Eu me sinto presa ainda ao câncer, tu acreditas? Eu me sinto presa ao câncer (E5).

No caso dos relatos, embora sugerindo um sentido negativo, a dor, como um tributo e um fardo a ser carregado, traz um significado de que a esta é, ao mesmo tempo, a lembrança de sua sobrevivência e a esperança de continuar vivendo. Isso permite que as participantes consigam enfrentar e dar um sentido às suas vidas e à dor total sentida.

Os profissionais de saúde devem compreender e respeitar as formulaçóes dos seus pacientes, ao mesmo tempo em que os encoraja e os orienta de que não é necessário seguir com uma vida de dor, haja vista a disponibilidade de inúmeros tratamentos e cuidados clínicos e psicológicos que podem ajudar e atenuar o sofrimento.

\section{DOR COMO EXPRESSÃO DE AFETOS E APEGOS}

A dor como expressão de afetos traduz um sentido de ressignificação, adaptação e aceitação para um convívio em equilíbrio com a dor sentida. As falas são caracterizadas por um balanço geral da dor total sentida como um mosaico de afetos e apegos de desalento, raiva, luta, adaptação e aceitação.

E assim eu vou convivendo, aprendi a conviver. Porque no começo não foi fácil não, no começo foi bem difícil. Porque eu ficava pensando assim: 'Meu Deus, como é que vai ser? Eu conviver com isso desse jeito?'. Não é nada legal a pessoa tá sentindo dor e a gente ter que aprender a conviver com isso. $\mathrm{E}$ a gente acaba aprendendo, né. Acaba aprendendo a conviver com isso (E1).

Eu ia falar uma merda... É uma droga, é uma droga. (...) Tem dia que, eu falo pra você, (...). Eu já pensei em pedir pra cortar o braço pra vê se melhora. Porque dói (...) (E4).

Segundo McCracken ${ }^{28}$, a aceitação da dor leva o paciente a conhecê-la e controlá-la melhor, esforçando-se para ter uma vida satisfatória, apesar dela. Isto implica em relatos de intensidade mais baixa, menos ansiedade e sintomas depressivos, e menos incapacidade física e psicossocial.

Mas eu sou obrigada a conviver com a dor. Ela me atrapalha no dia a dia, é claro que me atrapalha. Mas náo por isso eu vou me prostrar em cima da cama e vou ficar lamentando, chorando, tentando piorar minha depressão (E3). 
Porque limita a gente, limita, entendeu? Então, eu náo sei qual é o efeito de vocês assim, mas eu acho que devia acabar, devia acabar. Porque você passou pelo teu processo todo. (...) Você fica condicionada ali a tomar aqueles remédios todo dia, todo dia. Se você náo tomar, você sente dor (E5).

A aceitaçáo da dor nessas sobreviventes não foi apenas uma decisão racional, mas um longo processo de aceitação e formulaçáo de uma nova identidade que envolve uma complexa mistura de emoçóes desagradáveis e incertas com a dor crônica, e também uma convivência como o sofrimento no futuro ${ }^{29}$. Enquanto a palavra dor se concentra em uma parte do nosso corpo, aquela que fere e, por assim dizer, desarticula, a palavra sofrimento se refere mais à atitude com a qual um indivíduo pode suportar essa dor e até viver com ela.

Então, eu convivo com a minha dor. (...) Agora eu aceito, é uma aceitação que eu tenho na minha vida que tem que fazer o tratamento, entendeu? (E5).

(...) no começo foi muito difícil aceitar, muito. Agora, agora eu já sei como é que funciona. Mas no começo foi difícil. (...) o jeito é você se adaptar. A verdade é essa, eu me adaptar a levar minha vida com dor (E2).

O sofrimento é uma experiência essencialmente alteritária ${ }^{30}$. O outro está sempre presente para a subjetividade sofredora. Esta se dirige a ele com o seu apelo e the endereça uma demanda ${ }^{30}$. Para Bordelois ${ }^{31}$, o sofredor é forçado a levantar a dor em seus braços como se ela fosse uma criança, e convocar toda a sua energia para continuar em pé, levando-a, pedindo ajuda, pedindo para ser escutado ${ }^{30}$.

Essa atitude tem a ver com a possibilidade vital e moral de integrar a dor em sua vida sem a deixar ser completamente alienadas dela. Daí a sua dimensão de atividade, na qual se inscreve sempre a interlocução na experiência do sofrimento.

O que eu sentia antes é... agora eu sou outra. Porque agora eu convivo com a doença [a dor] mais tranquila, bem mais tranquila (E1).

A ressignificação da dor pela expressão de afetos é o caminho que as participantes apresentam como processos vitais e identitários ${ }^{32}$ de adaptação e convívio com a dor. $\mathrm{O}$ reconhecimento desse processo auxilia tanto a equipe de saúde quanto os pacientes no encaminhamento das melhores práticas e cuidados em situaçôes clínicas de doenças crônicas nas quais impera esse tipo de dor total sentida.

\section{CONCLUSÃO}

Neste trabalho, a união da hermenêutica com a dialética permitiu uma compreensão mais ampla da experiência de dor crônica em sobreviventes de longo prazo de câncer de mama. A sobrevivência é experenciada como um processo de transição, aceitação e construçáo de novas identidades biográficas que só são possíveis de serem compreendidas e cuidadas levando-se em conta as dimensões biológica, emocional, social e espiritual.

Os resultados sugerem uma explicação para a dor sentida, a partir da formulação de um balanço da experiência vivida pelas entrevistadas. Quatro abrangentes sentidos sociais ganham relevo no material empírico. Esses sentidos apontam, em termos biográficos, para a aceitação e a construção de uma nova identidade, por meio da expressão de um singular sofrimento decorrente da dor total sentida por essas sobreviventes. As narrativas partem de uma dor como fragmentação, murmúrio e monólogo do corpo, para uma situação de convívio, expressão de afetos e aceitação da dor como transição para sobrevivência.

Como implicações para a prática, o estudo reforçou a necessidade da estruturaçáo de uma linha de cuidados especializada, em níveis primário e terciário, curativa e paliativa, fundamentada na identificação precoce, tratamento e reabilitação da dor crônica. O cuidado humanizado na sobrevivência ao câncer deve ser centrado na escuta ativa e qualificado dessas narrativas de dor. Cuidar e tratar essas sobreviventes requer não somente consideraçóes estritamente biológicas ou apenas psíquicas. As questóes emocionais, familiares, socioculturais e econômicas também devem ser consideradas de forma integrada.

Neste trabalho, foram elencadas como limitação a não exploração do amplo universo da dor crônica associada às fases da sobrevivência do câncer de mama e a restrição do campo de pesquisa a uma unidade de acompanhamento da dor crônica. Como desdobramentos a serem feitos, destaca-se a importância de ampliar o número de pesquisas com sobreviventes de câncer de mama de longo prazo com quadros de dor crônica, principalmente quanto às necessidades e às reais possibilidades do Sistema Único de Saúde (SUS) em atendê-las.

\section{CONTRIBUIÇÕES}

Paloma Gomes contribui substancialmente na concepção e/ou no planejamento do estudo; na obtenção, análise e/ou interpretação dos dados; e na redação. Fernando Lopes Tavares de Lima e Antonio Tadeu Cheriff dos Santos contribuíram substancialmente no planejamento do estudo; na análise e/ou interpretaçâo dos 
dados; e na revisão crítica. Todos os autores aprovaram a versão final a ser publicada.

\section{DECLARAÇÃO DE CONFLITO DE INTERESSES}

Nada a declarar.

\section{FONTES DE FINANCIAMENTO}

Não há.

\section{REFERÊNCIAS}

1. Bray F, Ferlay J, Soerjomataram I, et al. Global cancer statistics 2018: GLOBOCAN estimates of incidence and mortality worldwide for 36 cancers in 185 countries. CA Cancer J Clin. 2018;68(6):394-424. doi: https://doi. org/10.3322/caac. 21492

2. Instituto Nacional de Câncer José Alencar Gomes da Silva. Estimativa 2020: incidência de câncer no Brasil. Rio de Janeiro: INCA; 2019.

3. Mullan F. Seasons of survival: reflections of a physician with cancer. N Engl J Med. 1985;313(4):270-3. doi: https://doi.org/10.1056/NEJM198507253130421

4. Glare PA, Davies PS, Finlay E, et al. Pain in cancer survivors. J Clin Oncol. 2014;32(16):1739-47. doi: https://doi.org/10.1200/JCO.2013.52.4629

5. Brown M, Farquhar-Smith P. Pain in cancer survivors; filling in the gaps. Br J Anaesth. 2017;119(4):723-36. doi: https://doi.org/10.1093/bja/aex202

6. International Association for the Study of Pain [Internet]. Washington, DC: IASP; c2018. IASP Terminology; [updated 2017 Dec 14; cited 2019 Jan 21]. Available from: https://www.iasp-pain.org /Education/Content. aspx?ItemNumber $=1698$

7. Miranda CCV, Seda Junior LF, Pelloso LRCA. New physiological classification of pains: current concept of neuropathic pain. Rev Dor. 2016;17(Supl 1):2-4. doi: https://doi.org/10.5935/1806-0013.20160037

8. Bennett MI, Kaasa S, Barke A, et al. The IASP classification of chronic pain for ICD-11: chronic cancerrelated pain. Pain. 2019;160(1):38-44. doi: https://doi. org/10.1097/j.pain.0000000000001363

9. Harrington CB, Hansen JA, Moskowitz M, et al. It's not over when it's over: long-term symptoms in cancer survivors--a systematic review. Int J Psychiatry Med. 2010;40(2):163-81. doi: https://doi.org/10.2190/ PM.40.2.c

10. Minayo MCS. Análise qualitativa: teoria, passos e fidedignidade. Cienc Saude Colet. 2012;17(3):621-6. doi: https://doi.org/10.1590/S1413-81232012000300007

11. Malterud K, Siersma VD, Guassora AD. Sample Size in Qualitative Interview Studies: Guided by Information
Power. Qual Health Res. 2016;26(13):1753-60. doi: https://doi.org/10.1177/1049732315617444

12. Attride-Stirling J. Thematic networks: an analytic tool for qualitative research. Qualitative Research. 2001;1(3):385405. doi:https://doi.org/10.1177/146879410100100307

13. Turk DC, Okifuji A. Psychological factors in chronic pain: evolution and revolution. J Consult Clin Psychol. 2002;70(3):678-90. doi: https://doi.org/10.1037//0022006x.70.3.678

14. Krikorian A, Limonero JT. An integrated view of suffering in palliative care. J Palliat Care. 2012;28(1):419. doi: https://doi.org/10.1177/082585971202800107

15. Le Breton D. Antropologia do corpo. 4. ed. Petrópolis, RJ: Vozes; 2016.

16. Le Breton D. Anthropologie de la doleur. Paris: Éditions Métailié; 2012.

17. Bustos Domínguez R. Elementos para una antropología del dolor: el aporte de David Le Breton. Acta Bioeth. 2000;6(1):103-111. doi: http://doi.org/10.4067/S1726569X2000000100008

18. Zborowski M. Cultural responses to pain. Sociology. 1952;8(4):16-30. doi: https://doi. org/10.1111/j.1540-4560.1952.tb01860.x

19. Andrews SH. Understanding pain in people who have had breast cancer [thesi on the Internet]. Leeds: University of Leeds; 2015 [cited 2020 Sept 14]. Available from: http://etheses.whiterose.ac.uk/10023/

20. Peretti-Watel P, Bendiane MK, Spica L, et al. Pain narratives in breast cancer survivors. Pain Res Treat. 2012;2012:153060. doi: https://doi. org/10.1155/2012/153060

21. Costa WA, Monteiro MN, Queiroz JF, et al. Pain and quality of life in breast cancer patients. Clinics (São Paulo). 2017;72(12):758-63. doi: https://doi. org/10.6061/clinics/2017(12)07

22. Spica L, Bendiane MK, Peretti-Watel P, et al. L'expérience de la douleur parmi des femmes atteintes d'un cancer $\mathrm{du}$ sein (cohorte ELIPPSE) [Pain and breast cancer among women from the ELIPPSE cohort]. Bull Cancer. 2010;97(8):909-16. doi: https://doi.org/10.1684/ bdc. 2010.1133

23. Bao T, Seidman A, Li Q, et al. Living with chronic pain: perceptions of breast cancer survivors. Breast Cancer Res Treat. 2018;169(1):133-40. doi: https://doi. org/10.1007/s10549-018-4670-9

24. Armoogum J, Harcourt D, Foster C, et al. The experience of persistent pain in adult cancer survivors: a qualitative evidence synthesis. Eur J Cancer Care (Engl). 2020;29(1):e13192. doi: https://doi.org/10.1111/ ecc. 13192

25. Salik AG. O paciente oncológico e suas relaçóes de encontro. Rev SBPH [Internet]. 2013 [acesso 2020 maio 12];16(2):89-102. Disponível em: http://pepsic. 
bvsalud.org/scielo.php?script=sci_arttext\&pid=S151608582013000200007\&lng=pt.

26. Williams ACC, Craig KD. Updating the definition of pain. Pain. 2016;157(11):2420-3. doi: https://doi. org/10.1097/j.pain.0000000000000613

27. Miceli AVP. Dor crônica e subjetividade em oncologia. Rev Bras Cancerol. 2002;48(3):363-73.

28. McCracken LM. Learning to live with the pain: acceptance of pain predicts adjustment in persons with chronic pain. Pain 1998;74(1):21-7. doi: https://doi. org/10.1016/s0304-3959(97)00146-2

29. Ojala T, Häkkinen A, Karppinen J, et al. Revising the negative meaning of chronic pain - A phenomenological study. Chronic Illn. 2015;11(2):156-67. doi: https://doi. org/10.1177/1742395314555236

30. Santos WJ, Giacomin KC, Firmo JOA. Alteridade da dor nas práticas de Saúde Coletiva: implicaçóes para a atenção à saúde de pessoas idosas. Cienc Saude Colet. 2015;20(12):3713-21. doi: https://doi. org/10.1590/1413-812320152012.19382014

31. Bordelois I. ¿Qué nos dice el lenguaje acerca del dolor? [What does language tell us about pain?]. Vertex [Internet]. 2013 [cited 2020 maio 12];24(111):363-7. Available from: http://polemos.com.ar/docs/vertex/ vertex111.pdf

32. Bury M. Chronic illness as biographical disruption. Sociol Health Illn. 1982;4(2):167-82. doi: https://doi. org/10.1111/1467-9566.ep11339939 